BULLETIN Bulletin hispanique

HISPANIQUE Université Michel de Montaigne Bordeaux

$110-2 \mid 2008$

Varia

\title{
El verso 20 del Cantar de Mio Cid a la luz del Perceval
}

\section{Alfonso Boix Jovaní}

\section{OpenEdition}

Journals

Édition électronique

URL : http://journals.openedition.org/bulletinhispanique/787

DOI : 10.4000/bulletinhispanique.787

ISSN : 1775-3821

Éditeur

Presses universitaires de Bordeaux

Édition imprimée

Date de publication : 1 décembre 2008

Pagination : $559-571$

ISBN : 978-2-86781-543-0

ISSN : 0007-4640

Référence électronique

Alfonso Boix Jovaní, «El verso 20 del Cantar de Mio Cid a la luz del Perceval », Bulletin hispanique [En ligne], 110-2 | 2008, mis en ligne le 01 décembre 2011, consulté le 21 décembre 2020. URL : http:// journals.openedition.org/bulletinhispanique/787 ; DOI : https://doi.org/10.4000/bulletinhispanique. 787

Tous droits réservés 


\title{
VARIÉTÉS
}

\section{El verso 20 del Cantar de Mio Cid \\ a la luz del Perceval*}

\author{
Alfonso Boix Jovaní \\ Castellón de la Plana - España
}

Para Alberto Montaner, por todo.

Cet article propose un rapprochement entre le célèbre vers 20 du Cantar de Mio Cid et les vers 992-993 du Perceval de Chrétien de Troyes. La comparaison offre de nouvelles perspectives d'interprétation pour "Dios, qué buen vasallo si oviesse buen señor». Les études antérieures de ce vers $d u$ Cantar sont prises en compte afin de savoir si elles corroborent cette nouvelle analyse ou pour les confronter aux interprétations qui surgissent à partir de la comparaison avec le texte de Chrétien.

Este artículo desarrolla un análisis comparativo entre el famoso verso 20 del Cantar de Mio Cid y los versos 992-993 del Perceval de Chrétien de Troyes. Estos fragmentos muestran diversas similitudes entre sí, y su comparación ofrece nuevas perspectivas e interpretaciones para "Dios, qué buen vasallo si oviesse buen señor". Por supuesto, las

* El presente estudio forma parte de las actividades desarrolladas en el marco del Proyecto del Plan Nacional de I + D + I con código HUM2005-05783/FILO: «Génesis y Evolución de la Materia Cidiana en la Edad Media y el Siglo de Oro», financiado por el Ministerio de Educación y Ciencia y cofinanciado con FEDER.

$B H i$, Tome 110, n 2 - décembre 2008 - p. 559 à 571. 
opiniones previas aportadas por los investigadores que ya estudiaron el verso del Cantar de Mio Cid son tenidas en cuenta a fin de saber si apoyan este nuevo análisis o, por el contrario, para comprobar su validez frente a las interpretaciones que surgen a partir de la comparación con el texto de Chrétien.

This article proposes bringing together the famous verse 20 in the 'Cantar de Mio Cid', and verses 992-993 in Chrétien de Troyes' 'Perceval'. The comparison offers new interpretation perspectives for "Dios, qué buen vasallo si oviesse buen señor». The previous studies on that verse from the 'Cantar de Mio Cid' are taken into account in order to know whether they corroborate this new analysis - as well as to check their validity against the interpretations that arise from their comparison with Chrétien's text.

Mots-clés : Cantar de Mio Cid - Perceval - Vassal - Seigneur.

\section{Introducción}

“i Ios, qué buen vassallo, si oviesse buen señor!» ${ }^{1}$. Quizá sea éste el más famoso de todos los versos del Cantar de Mio Cid (CMC, en adelante), incluso por encima del actual verso primero. Su polémico significado es en gran parte responsable de su fama, pues todavía no ha quedado totalmente claro su sentido. Ha habido dos interpretaciones básicas ${ }^{2}$, que Deyermond (1987: 28) supo resumir, plasmando a la vez la oscuridad del v. 20, en una pregunta retórica, recurso genial para tal propósito: «¿quiere decir «¡Ojalá que tuviese buen señor!» o "Sería buen vasallo si tuviese buen señor»?». Como caso aparte queda la explicación de Garci Gómez, sin apenas base a mi parecer (vid. Apéndice). Con sus diversas matizaciones, estas dos posibles interpretaciones han sido concienzudamente revisadas por Montaner (1993: 105 y 394-395), análisis al que remito y tras el cual el autor resuelve que:

Teniendo en cuenta la mentalidad feudal y los efectos jurídicos de la ira regia, la interpretación que parece más adecuada es la segunda: el exiliado dejaba de ser vasallo de su

1. Cito los pasajes del Cantar de Mio Cid por la edición de Montaner (1993).

2. Y que han generado una importante bibliografía. Para conocer los diversos aspectos de las interpretaciones, con sus matices, vid. especialmente Alonso (1944), Spitzer (1946), Badía Margarit (1954), Ridruejo (1985), López Estrada (1982: 63-68) y las consideraciones, a partir de la revisión de diversos estudios, de Chalon (1976: 134-135) y muy especialmente de Montaner (1993: 394-395). 
rey y, para subsistir, solía buscar a un nuevo señor al que prestar sus servicios (cf. Partidas, IV, xxv, 8 y II). Como, mientras tanto, no era vasallo de nadie, la frase ha de tener sentido condicional, y con ella los ciudadanos de Burgos expresan las posibilidades que se le abren al Cid en el destierro. [...] De este modo, se acusa veladamente al rey de haber repudiado a tan buen vasallo, pero, a la vez, se permite identificarlo en el futuro con ese buen señor que el Cid recobrará desde el exilio. (Montaner 1993: 394-395)

El análisis que aquí se inicia apoyará la interpretación que defiende Montaner, aunque discurriendo por vías distintas de las hasta hoy trazadas, centrándome en elementos puramente literarios que, según creo, no se han tenido en consideración a la hora de analizar el v. 20 y que sí ayudan a comprender algunas de las ideas que parece llevar implícitas.

\section{El v. 20 del $C M C$ y los vv. 992-993 del Perceval}

La similitud entre el v. 20 y el v. 3164 del manuscrito oxoniense de la Chanson de Roland, o sus variantes del manuscrito Venecia IV y del de París ha sido puesta de relieve en numerosas ocasiones (Montaner 1993: $395)^{3}$, aunque, como bien advirtió Smith, su similitud estructural no se corresponde con un parecido semántico ${ }^{4}$. Sin embargo, la existencia de unos versos que, homológica y analógicamente, parecen guardar relación con el

3. Riquer apunta la similitud entre el v. 20 y el 3164 de la Chanson de Roland, «Deus! quel baron, s'oust chrestientet!» en la descripción de Baligant (1949: 258), e indica que «Bédier traduce este verso: «Dieu! quel baron, s'il était chrétien!». En mi opinión también podría interpretarse: «iDios, qué barón, si tuviera cristiandad!», o sea «si mandara cristianos». No obstante, tanto si preferimos una u otra interpretación, es evidente que el verso francés tiene extraordinario parecido con el castellano", lo cual es muy adecuado, pero remite a un parecido meramente formal, que no a su sentido profundo, como bien advirtió Horrent (1973: 362) al tratar la similitud entre el v. 20 del $C M C$ y el 3164 de la $C R$ e indicar que «tienen idéntica construcción, pero esta identidad formal no refleja una identidad ideológica. El poeta de Roland pretende que el pagano sería varón cabal si fuese cristiano. No cumpliendo con esta condición, no merece el nombre de caballero perfecto. ¿Podemos pretender que el Cid no es buen vasallo porque no tiene buen señor? Sería contradictorio con el sentido profundo del poema que manifiesta con gran poder sugestivo que el Cid es buen vasallo aunque no tiene buen señor».

4. «Es cierto que no sabemos cómo hay que entender gramaticalmente el verso español, ni por tanto cómo puntuarlo, y es seguro que el pensamiento del poeta no tiene nada que ver con el pensamiento de "Turoldo" acerca de Baligant. Lo que quería decir Per Abad con este verso es un asunto muy debatido.» (Smith 1985: 256-257). 
v. 20 del $C M C$, pueden contribuir a resolver el sentido del mismo. Se hallan en el Perceval de Chrétien de Troyes, allí donde el rey Arturo comenta acerca de Perceval:

qu'il a esté a malvais mestre;

encore puet preus vassax estre. (vv. 992-993) ${ }^{5}$

Los versos «y que ha tenido un mal maestro; / mas podría ser un valioso vasallo» recuerdan en gran medida al v. 20 del CMC: una estructura bimembre con ese "preus vassax» que recuerda al «buen vasallo» del $C M C$, y la presencia de un superior a ese vasallo, el «malvais mestre», que puede relacionarse con el «buen señor» del poema cidiano. Es interesante tener en consideración que el famoso «si» del CMC, que tanto ha dado que hablar ${ }^{6}$, no aparece en los versos franceses (en su lugar figura «encore»), ausencia que obliga a basar el sentido de los versos francos en otros elementos, más allá de una conjunción. Esos mismos elementos pueden contribuir a ahondar en el significado del v. 20 del $C M C$.

\section{Comparación de los versos}

Los vv. 992-993 del Perceval vienen precedidos de una larga narración en la que se informa al lector sobre el protagonista principal, su pasado, las razones por las que residió en la Yerma Floresta Solitaria, y su alejamiento de la orden de caballería, motivo fundamental que permite la existencia de la primera parte de la obra, una primera parte que esos vv. 992-993 condensan magistralmente: "qu'il a esté a malvais mestre» (referido a aquello que el lector conoce hasta ese momento, el pasado y presente inmediato del héroe

5. La copia Guiot registra estos versos en vv. 1015-1026.

6. Su importancia a la hora de interpretar el v. 20 desde la perspectiva tradicional pidaliana o la abierta por Amado Alonso queda reflejada en esta indicación de Menéndez Pidal (19441946: III, 1221): «Amado Alonso (Revista de Filología Hispánica, VI, 1944, págs. 187-191) propone leer en el verso 20: ¡Dios qué buen vassallo! jSi oviesse buen señor!, entendiendo sí como adverbio optativo igual al moderno 'asi' [...]. Nos inclina a aceptar esta interpretación la brillante defensa que de ella hace A. Alonso, y el mismo sabor arcaico que da al pasaje. No es, empero, contundente la razón ideológica ahí propuesta contra el si condicional: "la frustración del héroe como buen vasallo por no tener buen señor, es contraria al pensamiento poético". Hay que tener presente que el Cid, al ser desterrado, dejaba de ser vasallo del rey Alfonso y tenía que buscar otro señor a quien servir; por eso el si condicional puede avenirse mejor con el hecho del destierro: ¡qué buen vasallo pierde Alfonso por no ser buen señor, desterrando al héroe!». 
que, hasta ese momento, no ha tenido buen maestro; en realidad, no ha tenido ninguno) y «encore puet preus vassax estre» (referido al futuro, a los derroteros por los que discurrirá la narración, pues Perceval aprenderá lo necesario para ser no ya un buen vasallo, sino un excepcional caballero).

Frente a él, y en buena medida a causa de la ausencia del primer folio del $C M C$, no sabemos exactamente qué decían aquellos versos que abrieron un día el cantar cidiano, ni si existiría algún término que remitiese al v. 20. Sin embargo, pese a esta falta, sabemos que el rey Alfonso desterró al Cid por el asunto de las parias. Además, el v. 20 tiene una similitud fundamental con los vv. 992-993 del Perceval, de acuerdo con su posición dentro del texto al que pertenecen. Pese a encontrarse cerca del v. 1000, los versos del Perceval aparecen cuando el galés todavía no ha iniciado la andadura que le llevará a ser admirado en la corte artúrica. Del mismo modo, el v. 20 figura en el momento en que el Cid está partiendo hacia el destierro, también en el inicio de las andanzas del Campeador.

Ahora bien, Arturo advierte esto a Keu justo después de que su senescal haya dicho al galés que salga en busca de las armas del Caballero Bermejo. Pero lo interesante es advertir que no tendría ningún sentido la presencia de esos "qu'il a esté a malvais mestre; / encore puet preus vassax estre», si la narración no tuviese nada que ver con ellos, esto es, si la andadura de Perceval no le llevase a recibir la formación necesaria. Visto así, es evidente que la advertencia de Arturo a Keu es también una indicación sobre cuál será la trama de su narración. Se trata, al fin y al cabo, de los versos que muestran el «hecho inicial (un ultraje, un rapto, la conciencia de una desaparición o una ausencia, algo, en fin, que hay que vengar o recuperar), que dispara al caballero hacia su arriesgado errar en pos de una meta lejana» (García Gual 1988: 263-264), es decir, una carencia inicial desde la cual parte el héroe, y que tendrá que compensar. En efecto, Chrétien de Troyes no nos da estas indicaciones para hacer fracasar en este aprendizaje a su protagonista: el autor maneja la trama para que derive hacia el final que la audiencia espera, esto es, el éxito del héroe.

Creo que, al igual que los vv. 992-993 del Perceval servían para indicar en qué se basaría la andadura del joven galés, este v. 20 del $C M C$ puede estar haciendo referencia a lo que desean los burgaleses, y, con ellos, también la audiencia del juglar: si las palabras de Arturo remitían a una futura reparación de la ignorantia que sufría Perceval por su aislamiento en el bosque, el v. 20 apuntaría a la reparación de la desastrosa situación en que el Campeador se halla al inicio de su cantar, esto es, que el destierro del Cid termine algún día y que el rey Alfonso VI acepte al Cid como vasallo, reparando su errónea 
decisión ${ }^{7}$. En ambos casos, las carencias iniciales de los héroes quedarían compensadas (en el caso del Campeador, su carencia inicial es la pérdida del amor regio). Y no puede ser que los burgaleses deseasen que el Cid encontrase a otro señor al que servir porque, de haber sido así, ¿sería ese el final que querría la audiencia? ¿ver a su héroe sirviendo a otro que no fuese su «seńor natural»? En absoluto, no ya por un mero sentido patriótico, sino porque no encaja con la trama del poema: era necesario que el Cid fuese perdonado por el mismo rey que le había desterrado o, de lo contrario, no habría recuperación del honor y los «enemigos malos» habrían logrado sus propósitos. El héroe no estaría donde le correspondía por derecho ni el monarca repararía el error de haberle echado de su lado.

Esta idea se reafirma con las palabras de Minaya en la segunda embajada, quien califica al rey como «buen señor»:

$\begin{array}{ll}\text { Besávavos las manos } & \text { mio Cid lidiador, } \\ \text { los pies e las manos } & \text { commo a tan buen señor, (vv. 1322-1323) }\end{array}$

En efecto, el rey Alfonso estaba pasando a ser el buen señor que reclamaban los burgaleses ${ }^{8}$, pues muestra clara simpatía hacia el Cid: al regreso de la segunda embajada, Minaya portaba no sólo buenas nuevas, sino la preciosa compañía de Jimena y sus hijas, a las que el monarca había dado permiso de marchar junto a Rodrigo.

Todo lo expuesto hasta aquí en torno al v. 20 viene apoyado a su vez por la idea de Montaner (1993: 395), para quien, en el v. 20 del CMC, «se acusa veladamente al rey de haber repudiado a tan buen vasallo, pero, a la vez, se permite identificarlo en el futuro con ese buen señor que el Cid recobrará desde el exilio».

\section{III. ¿¿Es el "Señor" del v. 20 el rey Alfonso VI? Una respuesta estructural}

Ya hasta aquí se contempla cómo el v. 20, al ser comparado con toda la trama del CMC, parece hacer referencia a Alfonso VI. Sin embargo, deseo reforzar esa identificación entre el rey del Cid y el «buen señor», lo cual se

7. Discrepo, por tanto, de la hipótesis de Simón (vid. Bibliografía), pues me parece muy arriesgada y compleja, pese a la brillante defensa de su teoría, según la cual debería interpretarse el v. 20 como «¡Dios, qué buen vasallo! ¡Ojalá tuviese bienes, Señor!” (cito según la referencia de la autora en su artículo), en una doble invocación al Altísimo.

8. «aquí Alfonso empieza a ser de nuevo el buen señor anhelado para el Cid en el verso 20» (Montaner 1993: 184, n. 1322-1323). 
obtiene al considerar al v. 20 no de manera aislada, sino dentro del texto en que figura. Sin duda, los burgueses estaban pensando en el Cid al referirse al «buen vasallo», pues le contemplaban a su paso por Burgos:

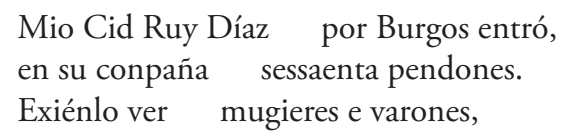

(vv. 15-16b)

Pero, recién expresado el verso 20, se pasa directamente a hablar de los durísimos términos con los que el rey ha prohibido la ayuda al Campeador. Visto así, la primera mitad del v. 20, el «-¡Dios, qué buen vassallo», sirve como referencia anafórica al Cid, de quien se ha hablado hasta ese momento, mientras que «si oviesse buen señor!» actúa como referencia catafórica al rey, de quien se procederá a hablar en ese momento. El v. 20, que hace clara referencia al problema que sufre el Cid, separa a su vez a las dos partes litigantes, Rodrigo y Alfonso. La mirada va al Cid, y la mente al rey Alfonso. A partir del v. 20, como en un flash-back, se expone por qué los burgueses no creen que el rey esté actuando correctamente: porque, frente al buen vasallo, el rey no es «buen señor», pues con tanta sańa se porta contra el buen Cid. Es necesario considerar que, tal vez, los burgaleses permanecen en la ignorancia, y no saben que han sido malos nobles los que han enfrentado a Alfonso VI con el Cid. Al fin y al cabo, los judíos no saben nada de los malos nobles que han soliviantado al rey contra el Cid. Aunque no creo que el autor quisiera dejar a los de Burgos como ignorantes, no es imposible, ni mucho menos, que no sepan de los malos mestureros. Visto el v. 20 desde esa ignorancia, pese a la cual muestran su estima al Campeador, y sumando además las órdenes regias que prohíben la ayuda al Cid, no es extraño que a los habitantes de la ciudad el rey les pareciese un tirano, al menos en ese momento.

\section{IV. ¿Un mal rey?}

Pero la dureza de las prohibiciones son, probablemente, sólo parte de las razones que tenían los burgueses para afirmar que el rey no estaba actuando como un «buen señor». La aparente dureza del verso hacia Alfonso VI constituye uno de sus puntos más oscuros, pues es verdaderamente llamativo que el $C M C$ critique al rey Alfonso, ya que el v. 20 descarta, según parece, al rey como un buen señor, pues obliga a marchar al buen vasallo. Sin embargo, 
es extraño que el autor quisiera ofrecer una visión del rey como mal Señor, habida cuenta que era el mismo que tenía que perdonar al Cid, y aún más cuando el mismo Cid es quien exculpa a Alfonso VI de toda responsabilidad en su desgracia, como reflejan los conocidos vv. 8-9: «-¡Grado a ti, Señor, Padre que estás en alto! / ¡Esto me an buelto mios enemigos malos!-».

El paralelismo entre el Perceval y el CMC permite explicar también el sentido de este verso. En efecto, establece una conexión entre buen señor [rey]-buen vasallo, como sucede con el Perceval en la relación maestrodiscípulo ( = vasallo, en el Perceval, pues el aprendizaje radica en aprender a ser caballero y, con ello, buen vasallo). La estructura alterada del v. 20 parece remitir a que, al igual que no puede haber discípulo sin maestro, no puede haber vasallo sin un señor, en este caso el rey, y viceversa.

No andaba Bandera Gómez desencaminado al advertir sobre el v. 20 que «el Cid no es bueno a secas, sino buen vasallo, con lo cual su bondad encaja dentro de un orden preestablecido de relaciones de tipo social» (Bandera Gómez 1969: 46). Pero se quedó a medio camino pues, aplicando este razonamiento a la figura regia, el v. 20 no se refiere a si los protagonistas son buenos o malos moralmente, sino a si cumplen bien o no su función en esa relación recíproca señor-vasallo: el Cid es buen vasallo, cumple con sus deberes para con Alfonso, pero éste no cumple como un señor debiera hacia un vasallo fiel, sino que lo destierra. Que el Cid sea un buen vasallo no se refiere a que sea una persona de catadura moral intachable, sino que sirve a su señor como todo vasallo debiera hacer correctamente $-\mathrm{y}$, de hecho, es lo que demostrará a lo largo del destierro. Siguiendo el paralelismo con Perceval, el «mal maestro» del galés no nos remite a un maestro malvado. No parece adecuado pensar que ese «malvais mestre» quiera dar a entender que Perceval tuvo un maestro malvado, sino que era poco hábil en sus funciones. La queja hacia el rey va referida a su actuación poco hábil, a no haber cumplido bien su cometido ${ }^{9}$. Y, en efecto, la misión del héroe en el $C M C$ será reparar no

9. No estoy de acuerdo con Walker (1976: 258) cuando se refiere al v. 20 como «the only anti-Alfonso sentiment is the pious cry of the people of Burgos», pues no creo que sea en absoluto anti-alfonsino, ni con De Chasca (1953: 184) cuando dice sobre el v. 20 que «its unmistakable anti-Alfonsine and pro-Cidian sentiment, a sentiment resulting from the unfavourable opinion which the citizens of Burgos have of the king's conduct.», ni cuando define a Alfonso como «the grudging tyrant of the first Cantan (1953: 189) al compararlo con el gran y justo rey de la segunda parte del CMC. Pero sí acierta al indicar que «it is not proper for the perfect knight nor for any of his followers or relatives to blame the king even if he is not blameless. Neither is it fitting for the people to give open expressions for their disapproval, although their censure does not fail to make itself felt indirectly. The King can do no wrong, but what a pity that he should not be as perfect as his vassal!» (1953: 184), del que se desprende no su maldad «espiritual», sino que no ha actuado bien como rey. 
esa maldad, que no la hay, sino la decisión errónea de su monarca, al igual que Perceval tiene por misión aprender de la caballería lo que su madre le impidió conocer para protegerle. En ambos casos, decisiones erróneas que perjudicaron al protagonista, pero nunca motivadas por la maldad de Alfonso VI o de la Dama Viuda.

Además, si el rey no es, en el momento en que los burgaleses expresan este lamento, un señor benévolo, no es por culpa de él sino, de acuerdo con la citada relación señor-vasallo, por culpa de vasallos. El rey ha actuado de manera equívoca al expulsar al buen vasallo, y se rodea de malos vasallos. En resumen, los malos vasallos hacen de un rey un monarca injusto. Esto tendría mucho sentido en cuanto que conectaría al v. 20 con aquellos vv. 8-9. Por otro lado, como es obvio, y al igual que los vv. 8-9 califican a los enemigos del Cid como malos mestureros, el v. 20 estaría apuntando no sólo la evolución del Cid, sino también la del rey, que irá paralela a la del Campeador. En efecto, el Cid, conforme vaya haciendo méritos, irá ganándose la confianza y el amor de su rey, quien también evolucionará, dándose cuenta del error que cometió al expulsar al Cid, y pasando a ser un buen señor al aceptar a Rodrigo de nuevo entre su mesnada. Este paralelismo, por otro lado, refuerza ideas que ya expresó Montaner con respecto a la conexión entre los vv. 8-9, 14 y 20 del $C M C$ (2001: 459):

[con los vv. 8-9] se podría representar lo pasado (la calumnia que ha provocado la ira regia), [con el v. 14] el presente (la esperanzada marcha al destierro) y [con el v. 20] el futuro (el reencuentro del buen vasallo y el buen señor).

Como puede apreciarse, Montaner entendió el v. 20 como un verso que presagiaba el reencuentro entre el Cid y el rey Alfonso, lo cual viene confirmado por las observaciones expuestas a lo largo del presente estudio.

\section{Conclusión}

La comparación de los vv. 992-93 del Perceval con el v. 20 del CMC permite apreciar ciertos aspectos que hasta ahora no habían recibido la consideración suficiente. Los versos franceses, con la ausencia de un «si» polémico como en el $C M C$, tienen sentido gracias a otros elementos -su posición en la narración y su función en ella, principalmente- que, aplicados al v. 20 del poema castellano, permiten clarificar el sentido de este complejo verso. 
Así, por tanto, creo que las dos soluciones tradicionales son correctas, pero era necesario esclarecer dos aspectos. En primer lugar, que el «buen señor» hace referencia a Alfonso VI; en segundo, que el verbo «oviesse» tiene un significado de futuro, en cuanto que remite a la trama que sigue desde ese punto en adelante. A partir de ahí, que el «si» sea o no condicional no deja de ser más que una cuestión gramatical, que orienta la lectura hacia el optativo o el condicional, pero no es clave para interpretar el v. 20.

\section{Bibliografía}

Alonso Amado, «iDios, qué buen vasallo! ¡Sí oviesse buen señore!», Revista de Filología Hispánica, VI (1944), pp. 187-191.

Armand Octavio, "El verso 20 del "Cantar de Mio Cid"», Cuadernos Hispanoamericanos, 269 (1972), pp. 339-348.

Bandera Gómez Cesáreo, El "Poema de Mio Cid": poesía, historia, mito, Madrid, Gredos, 1969.

Badía Margarit Antonio, «Sobre las interpretaciones del verso 20 del Cantar de Mio Cid», Archivum, IV (1954), pp. 149-165.

Chalon Louis, L'histoire et l'épopée Castillane du Moyen Âge. Le cycle du Cid. Le cycle des comtes de Castille, Paris, Honoré Champion, 1976.

Chasca Edmund de, «The king-vassal relationship in El Poema de Mio Cid», Hispanic Review, XXI (1953), pp. 183-192.

Deyermond Alan D., El «Cantar de Mio Cid» y la épica medieval española, Barcelona, Sirmio, 1987.

Garci Gómez Miguel, «Mio Cid». Estudios de endocrítica, Barcelona, Planeta, 1975.

García Gual Carlos, Primeras novelas europeas, Madrid, Istmo, 1988.

Horrent Jules, Historia y poesía en torno al "Cantar del Cid», Barcelona, Ariel, 1973.

López Estrada Francisco, Panorama critico sobre el Poema del Cid, Madrid, Castalia, 1982.

Lorenzo Criado Emilio (ed. y trad.), Cantar de los Nibelungos, Madrid, Cátedra, 2001.

Menéndez Pidal Ramón, Cantar de Mio Cid. Texto, gramática y vocabulario, edición revisada, Madrid, Espasa-Calpe, 1944-1946, tres volúmenes [edición original en Madrid, Bailly-Baillière e hijos, 1908-1911].

Menéndez Pidal Ramón, La España del Cid, Madrid, Plutarco, 1929.

Montaner Frutos, Alberto (ed.), Cantar de Mio Cid; con un estudio preliminar de Francisco Rico, Barcelona, Crítica, 1993.

Ridruejo, Emilio, "Otra vez sobre el verso 20 del Cantar de Mio Cid», Philologica Hispaniensia in honorem Manuel Alvar, II. Lingüistica, Madrid, Gredos, 1985, pp. 589-601. 
Riquer Martín de, «¡Dios, que buen vassallo, si oviesse buen señor!», Revista Bibliográfica y Documental, III (1949), pp. 257-259.

Spitzer Leo, «iDios, qué buen vassallo si oviesse buen señor!», Revista de Filología Hispánica, VIII (1946), pp. 132-135.

Smith Colin, La creación del «Poema de Mio Cid», Barcelona, Crítica, 1985 (edición original: The making of the "Poema de Mio Cid", Cambridge, Cambridge University Press, 1983).

Verjat Massmann Alain (ed. y trad.), Chrétien de troyes, El cuento del GrialLi contes del Graal; cronología, introducción, traducción inédita, bibliografía, notas, índice por Alain Verjat Massmann, Colección «Erasmo, textos bilingües», Barcelona, Bosch, 1995.

Walker Roger M., "The role of the King and the poet's intention in the Poema de Mio Cid", Medieval Hispanic Studies presented to Rita Hamilton, Londres, Tamesis Books, 1976, pp. 257-266.

\section{Apéndice: La interpretación de Garci Gómez}

En una original interpretación del v. 20, Garci Gómez (1975: 6277) propone que el «buen señor» haga referencia a Minaya Álvar Fáñez, apoyándose en los términos legales de vir bonus y bonus dominus, con un sentido de intermediario entre partes litigantes que muy bien puede ajustarse a la función de Minaya en el poema, al ser el embajador del Cid ante el rey.

No se sostiene, en primer lugar, que las gentes de Burgos, "personificando, más que ningún otro personaje, al auditorio del juglar, se conmovieron al ver al Cid en la desgracia más grande que podía acaecerle a un mortal: la ira del rey. Aunque no estuvieran libres de sospechas sobre la conducta del guerrero, en sus corazones cabía la lástima y la compasión; máxime cuando el desgraciado se mostraba compungido y, a imitación del paciente Job, daba gracias a Dios y ánimos a su acompañante. De verdad se portaba como buen vassalo» (p. 67), y aún menos su afirmación que no pueda pensarse que «los burgaleses creyeran al Cid inocente en un episodio, sospechoso en otro [se refiere a las sospechas de Rachel y Vidas, que creen que el Cid es un ladrón]» (p. 66): por un lado, el contraste entre los prestamistas y los burgaleses muestra la oposición entre ellos, entre quienes actúan de buena fe y los enemigos malos que quieren aprovecharse de la desgracia del Campeador. Por otro, ser un buen vasallo no radica en dar gracias a Dios o animar a los compañeros, sino en la fidelidad a un señor, y el v. 20 deja claro que el Cid es un buen vasallo. Por otro lado, la niña de nueve años que habla con el Cid, sin duda en representación de todos los burgaleses, deja claras las simpatías del pueblo hacia el ilustre hijo de Vivar. 
Sin embargo, diversos puntos hacen que su interpretación deba ser considerada con extremo cuidado. Como el propio autor admite, en la Edad Media «el home bono gozaba de una autoridad especial, superior, en casos dados, a la de los jueces; él [Minaya] era un juez extraordinario» (p. 72), afirmación arriesgada en extremo, pues no parece muy adecuado elevar a un intermediario a la categoría de juez, aún más cuando no está en sus manos decidir que el rey Alfonso acepte al Campeador. Solventa esto Garci Gómez con que «los individuos desavenidos [el Cid y el rey Alfonso] eran de mayor dignidad que cualquiera de los súbditos; lógicamente, el intermediario no se porta como juez autoritario y arbitrador, sino como mensajero (v. 1903). En poesía, que no es un documento legal auténtico, las funciones de los personajes se predican analógicamente; bajo esa analogía hemos de juzgar el papel de Minaya como de buen señon (p. 72). Es necesario recordar aquí, empero, la escrupulosidad con que el poeta utilizó la terminología legal que se exhibe a lo largo de todo el $C M C$. La diferencia con Garci Gómez es que no hay conexión entre ser un vasallo y ser un buen señor (como mediador), ni creo que de eso dependa la trama del CMC. No creo que quiera dejar todo el mérito a Álvar, cuando el mérito real será del Cid. No depende de Minaya que el Cid sea perdonado por el rey, ni es el propósito del CMC dar a entender que el perdón de Rodrigo depende de Âlvar Fáñez, sino de los propios esfuerzos del Campeador.

La exposición de Garci Gómez es apriorística, buscando en todo momento defender una teoría que deja clara bien pronto: «Los burgaleses, queriendo o sin querer, no hicieron otra cosa que dictar [en el v. 20] a los dos personajes centrales de la acción literaria sus respectivas normas de conducta: al Cid, que fuera siempre buen vassalo; a Álvar Fáńez, que hiciera de buen señon. A mi parecer, los burgaleses no piden nada al Cid, sino que ya dan por hecho, en presente, que es un buen vasallo. Además, el «exienlo ver»-que no «exienlos»-, del v. 16b, por lo que la mirada de los burgueses va al Cid, sin incluir a Minaya. Súmense, a todo esto, mis consideraciones a lo largo del artículo expuesto, para ratificar las dudas que suscitan las opiniones de Garci Gómez al respecto.

A todo esto habría que añadir las acertadas consideraciones de Ridruejo al respecto (1985: 590-91), que reproduzco a continuación:

Estos argumentos de Garci-Gómez no dejan de ser discutibles incluso desde un ángulo literario [...]. Es difícil poner en consonancia el cuadro que pinta el autor del Poema 
EL VERSO 20 DEL CANTAR DE MIO CID A LA LUZ DEL PERCEVAL

de los burgeses e burgesas "plorando de los ojos, tanto avien el dolor» (v. 18) con las sospechas que -si hacemos caso a Garci-Gómez- tienen sobre la conducta del Cid.

Por otra parte, no es de extrañar el comportamiento de Martín Antolínez con respecto a los hebreos, grupo especial de la literatura folklórica, en la cual atribuyen su propia avaricia al prójimo y desconfían por consiguiente, de su conducta. 
